\title{
Corrosion Inhibition of Low Carbon Steel in Hydrochloric Acid By
}

\section{Cardaria Draba Leaves Extracts}

\author{
Ahmed N. Abd", Anees A. Khadom ${ }^{* *}$ and Nagham Arif Ahmed ${ }^{*}$ \\ "Department of Chemistry, College of Science, Diyala University, Diyala, Iraq. \\ ${ }^{* *}$ Chemical Engineering Department, College of Engineering, Diyala University, Diyala, \\ Iraq.
}

Corresponding Author email: aneesdr@gmail.com

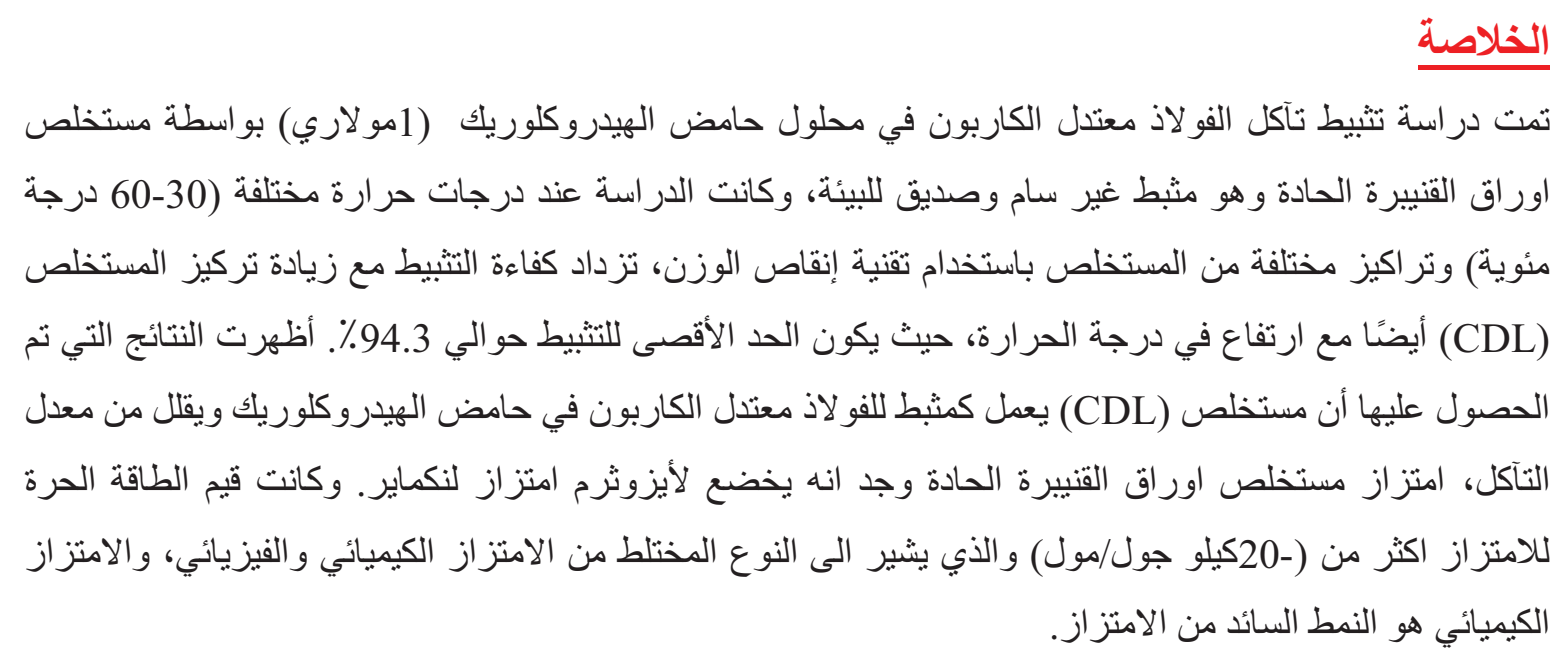

\section{$\underline{\text { Abstract }}$}

The corrosion inhibition of mild carbon steel in $1 \mathrm{M} \mathrm{HCl}$ solution was studied in presence of Cardaria Draba leaf extracts and his absence; it is a nontoxic and environmentally friendly inhibitor. The study was at different temperatures $\left(30-60^{\circ} \mathrm{C}\right)$ and different concentrations of extract using weight loss technique. the inhibition efficiency increases with increase in the concentration of the extract $(C D L)$ also with rising in temperature, where the maximum inhibition is around (94.3\%). the results obtained showed that $(C D L)$ extract act as an inhibitor for mild carbon steel in $\mathrm{HCl}$ and reduces the corrosion rate. the adsorption of Cardaria Draba leaf extracts was found to follow Langmuir adsorption isotherm. The values of the free energy of adsorption were more than $(-20 \mathrm{~kJ} / \mathrm{mol})$, which is indicative of a mixed mode of chemical and physical adsorption, but chemical adsorption is the predominant mode of adsorption.

$\underline{\text { Keywords }}$ Corrosive, green inhibitors, mild carbon steel, adsorption. 


\section{Introduction}

Mild carbon steel uses in numerous industrial establishments due to good tensile strength, easy availability, low-cost and many other desirable characteristics[1]. mild steel corrosive in acid medium causes significant damage, and acidic solutions are widely using to remove unwanted crust and rusting in a lot of industrial procedure, the major trouble with the use steel are degradation by acidic solutions[2]. the used of corrosive inhibitors are one of the more effective measures to protect steel surfaces from corrosion in acidic mediums[3]. the inhibitory activity rely on concentrating of the inhibitor itself and type of alloy studied, most inorganic-organic and inhibitors are too expensive, environmentally friendly and toxic, as a result of increased environmental awareness and the negative impact of some chemicals, an alternative should be sought to replace organic and inorganic inhibitors to promote sustainable greening of the environment, new corrosion inhibitors was found, , benign, non-toxic, renewable, inexpensive and easily available in various parts of plant extracts [4] . the literature survey shows that most organic substances used as corrosion inhibitors can be adsorbent onto the steel surface by heteroatoms such as $\mathrm{N}, \mathrm{O}, \mathrm{S}$, $\mathrm{P}$, aromatic rings and multiple bonds, inhibit active sites and reduce corrosion rate, the corrosion inhibiting effect of the organic composite is associated with adsorption Characteristics, adsorption depends a condition, nature of steel surface, a chemical composition of inhibitor and the type of corrosion medium, studies indicate that adsorption of organic inhibitor depends mainly on some physical and chemical Characteristics of the particle linked to his active group, a electrons density the donor atom, the steric effect leads the forming a protection film from corrosive [5]. Cardaria draba leaf (CDL) are easily available, inexpensive, and plants common in Diyala province / iraq. at a current study, natural of corrosion inhibitor were extracted and tested to prevent the corrosion of mild carbon steel in $(1 \mathrm{M} \mathrm{HCl})$ at various operating conditions. 


\section{Experimental:}

\subsection{Sample preparation:}

Mild steel specimen are using for this study, and were a local source, it have the next chemical installation; $\mathrm{C}(0.0182 \%), \mathrm{Si}(0.0176 \%), \mathrm{Cu}(0.0169 \%), \mathrm{Mn}(0.394 \%), \mathrm{P}$ (less than $0.0005 \%)$, S $(0.0330 \%), \mathrm{Cr}(0.0333 \%)$, Mo (less than $0.001 \%)$, Ni (less than $0.001 \%$ ) ,Ti (0.002\%), Al (0.0491\%), As (less than 0.0005\%), B (less than 0.0005\%), Co (less than $0.001 \%$ ), $\mathrm{Ca}$ (more than $0.008 \%$ ), $\mathrm{Nb}$ (less than 0.001\%), Sn (less than $0.001 \%$ ), V $(0.0005 \%), \operatorname{Zr}(0.0078 \%)$ and the remainder is $\mathrm{Fe}$, each sample had its dimensions $(3 \times 1 \times 0.1 \mathrm{~cm})$ and the surface area is about $7 \mathrm{~cm}^{2}$, the samples were first annealed in the electric oven for one hour at a temperature of $600^{\circ} \mathrm{C}$, cooled to room temperature, these samples are rubbed using emery paper and gradually $(60,80,100,320,400)$, thereafter washes with faucet water and then with filtered water and drying up by tissue paper, immersing at benzene, acetone then drying once more, lastly keep in the desiccator until use, the weight of the samples is measured using a Four mattresses electronic balance, the dimension are measuring accurately using a special electronic Vernier, the steel samples are immersion in a $250 \mathrm{ml}$ beaker container containing $(200 \mathrm{ml}$ ) test solution (consists of $1 \mathrm{M} \mathrm{HCl}$ and inhibitor concentration) at the temperature $30-60^{\circ} \mathrm{C}$ for $(3 \mathrm{~h})$, after immersion is re- weight, and the variance at the weight of steel samples before exposure and after him is taken for different corrosion solutions, a weight loss determines in the presence of inhibitor and his absence $\left(30-60^{\circ} \mathrm{C}\right)$ and the inhibitor concentration used $(2,4,6,8,10 \mathrm{ml})$ each test is repeated twice and takes mean values [6].

\section{2 preparation of Cardaria draba leaf extractor:}

Cardaria draba leaf $(C D L)$, are easily available, inexpensive, and plants common in Diyala province / iraq, the leaf are collecting and dries by the shade, grind using the blender and turn into fine powdering, Preparing the extractor by escalation $(10 \mathrm{gm})$ from powdered dry at $(100 \mathrm{ml})$ of $(1 \mathrm{M}) \mathrm{HCl}$ for $3 \mathrm{~h}$, keep it night long, a product is filtered and the amount of leachate it is with limit $(50 \mathrm{ml})$, the using Himself acid as an solution to corrosion and parts with the volumes of $(2,4,6,8,10 \mathrm{ml}) /$ Liter of $(1 \mathrm{M} \mathrm{HCl})$. 


\subsection{Prepare of the corrosive medium:}

The corrosive medium was $1 \mathrm{M} \mathrm{HCl}$ Its molecular weight $(36.46 \mathrm{~g} / \mathrm{mole})$ Prepared from $36 \%$ analytical grad supplied by Central Drug House $(C D H)$, dilutes the acid with filtered water to prepared a $(1 M)$ hydrochloric acid solution, for all group of prepared experiments using an (1M) $\mathrm{HCl}$ solutions to avoidance of polluting effects.

\subsection{Weight loss technique:}

Corrosive rates of mild carbon steel were determined with the presence of several concentrations of the extract $(C D L)$ and his absence in the acid solution by weight loss method at temperatures of various, of the following equation the corrosion rate value calculates:

$$
\mathrm{CR}=\frac{\Delta W}{A \times T}
$$

Where/ A are a surface area in $\left(\mathrm{cm}^{2}\right), \Delta W$ are the weight wastage with $(\mathrm{g}), T$ is time of exposure in (day).

Using the following neutralization, the ratio of inhibitor efficiency calculates From the corrosion rate:

$$
I E \%=\frac{C R_{\text {uninhibit_-}} C R_{\text {inhibit }}}{C R_{\text {uninhibit }}} \times 100
$$

Where/ ( $\left.C R_{\text {inhibit }}, C R_{\text {uninhibit }}\right)$ is the corrosive rates in the presence and absence of different concentrations of inhibitor respectively.

\section{5 (SEM) Scanning Electron Microscope:}

The (SEM) (Model TESCAN Vega III, made in the Czech Republic ) it has been using to study morphology of mild carbon steel surface with the presence of Cardaria draba leaf extractor and his absence during the exposure period $3 \mathrm{~h}$ in $(1 \mathrm{M}) \mathrm{HCl}$ at the temperature of $30-60^{\circ} \mathrm{C}$.

\section{$2.6(F T-I R)$ Fourier Transform-Infrared Spectroscopy:}

(FT - IR) model (SHIMADZU FT-IR 8400S spectrophotometer, made in Japan), used to diagnose the active groups and molecular structure of the inhibitor of Cardaria draba leaf extract. 


\section{Results and discussion:}

\subsection{Weight loss measurements}

The results listing in table (1) show the inhibition efficiency and corrosion rate for Cardaria draba leaf extract (CDL) in $(1 \mathrm{M}) \mathrm{HCl}$ at temperatures of different $\left(30-60^{\circ} \mathrm{C}\right)$. the resulting obtained showed that the addition of the inhibitors limits the disintegration of mild steel by blocking its corrosive sites and hence decreases the weight loss and the corrosion rate and hence increases the inhibition efficiency, inhibitor efficiency and corrosion rate were assessment at different operating conditions, the figures $(1,2)$ show that with increasing temperature a corrosion rate increased and decreases with increased inhibitor concentration [7].

Table (1) The Corrosion rate data in(1M) $H C l$ at different conditions.

\begin{tabular}{|c|c|c|c|c|}
\hline $\operatorname{Exp}$ & $\left(C_{i} \mathrm{ml} / \mathrm{L}\right)$ & $T,{ }^{\circ} \mathrm{C}$ & (Corrosion rate $(g m d))$ & $(\% I E)$ \\
\hline 1 & \multirow{4}{*}{0} & 30 & 249.6 & 0 \\
\hline 2 & & 40 & 432 & 0 \\
\hline 3 & & 50 & 1219.2 & 0 \\
\hline 4 & & 60 & 2784 & 0 \\
\hline 5 & \multirow{4}{*}{2} & 30 & 50.88 & 79.62 \\
\hline 6 & & 40 & 73.44 & 83 \\
\hline 7 & & 50 & 141.6 & 88.39 \\
\hline 8 & & 60 & 261.6 & 90.61 \\
\hline 9 & \multirow{4}{*}{4} & 30 & 40.32 & 83.85 \\
\hline 10 & & 40 & 61.68 & 85.73 \\
\hline 11 & & 50 & 120.72 & 90.1 \\
\hline 12 & & 60 & 211.44 & 92.41 \\
\hline 13 & \multirow{4}{*}{6} & 30 & 42 & 83.18 \\
\hline 14 & & 40 & 54 & 87.5 \\
\hline 15 & & 50 & 108.72 & 91.09 \\
\hline 16 & & 60 & 204 & 92.68 \\
\hline 17 & \multirow{4}{*}{8} & 30 & 41.28 & 83.47 \\
\hline 18 & & 40 & 53.52 & 87.62 \\
\hline 19 & & 50 & 99.36 & 91.86 \\
\hline 20 & & 60 & 181.68 & 93.48 \\
\hline 21 & \multirow{4}{*}{10} & 30 & 37.2 & 85.1 \\
\hline 22 & & 40 & 45.6 & 89.45 \\
\hline 23 & & 50 & 88.32 & 92.76 \\
\hline 24 & & 60 & 158.88 & 94.3 \\
\hline
\end{tabular}




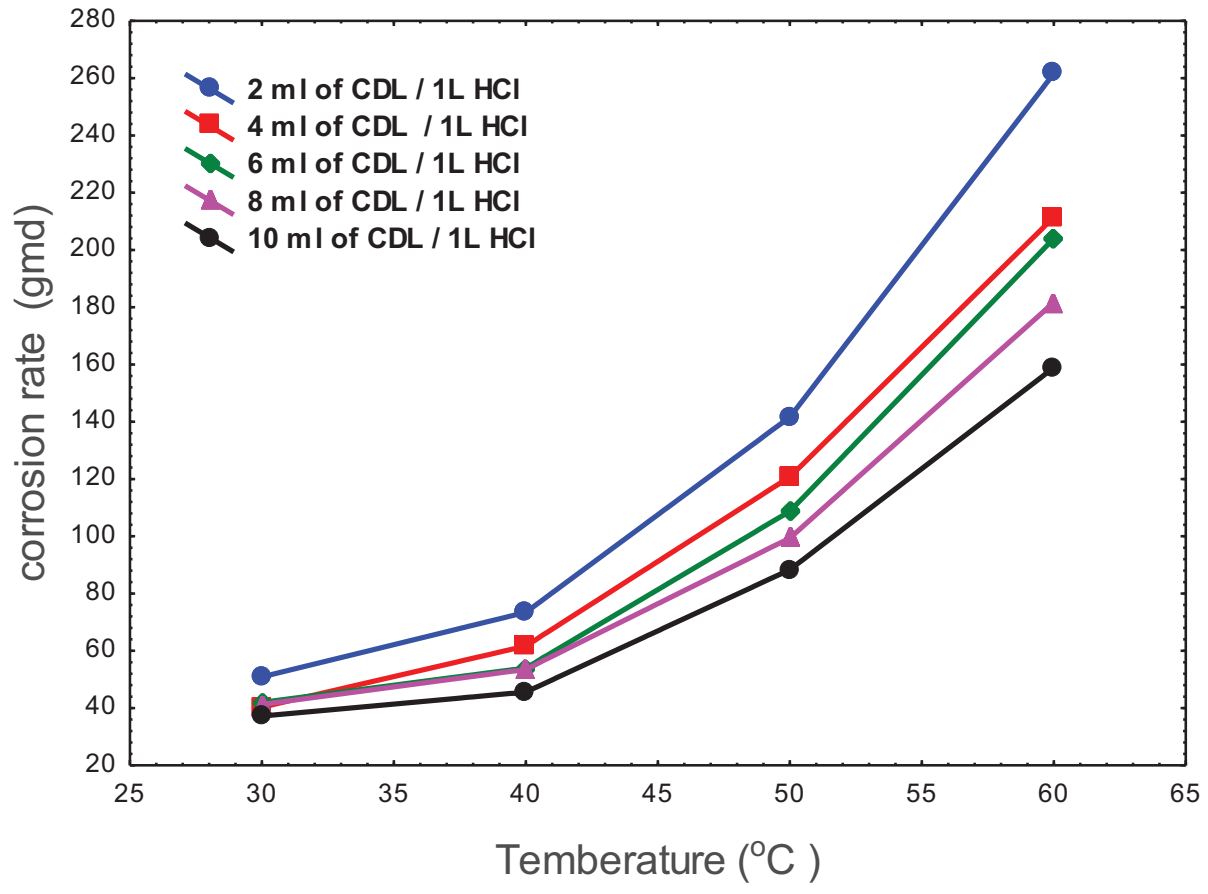

Fig. (1) Impact of temperature on the corrosion rate of mild carbon steel in $(1 \mathrm{M} \mathrm{HCl})$ at various concentrations of extract $(C D L)$.

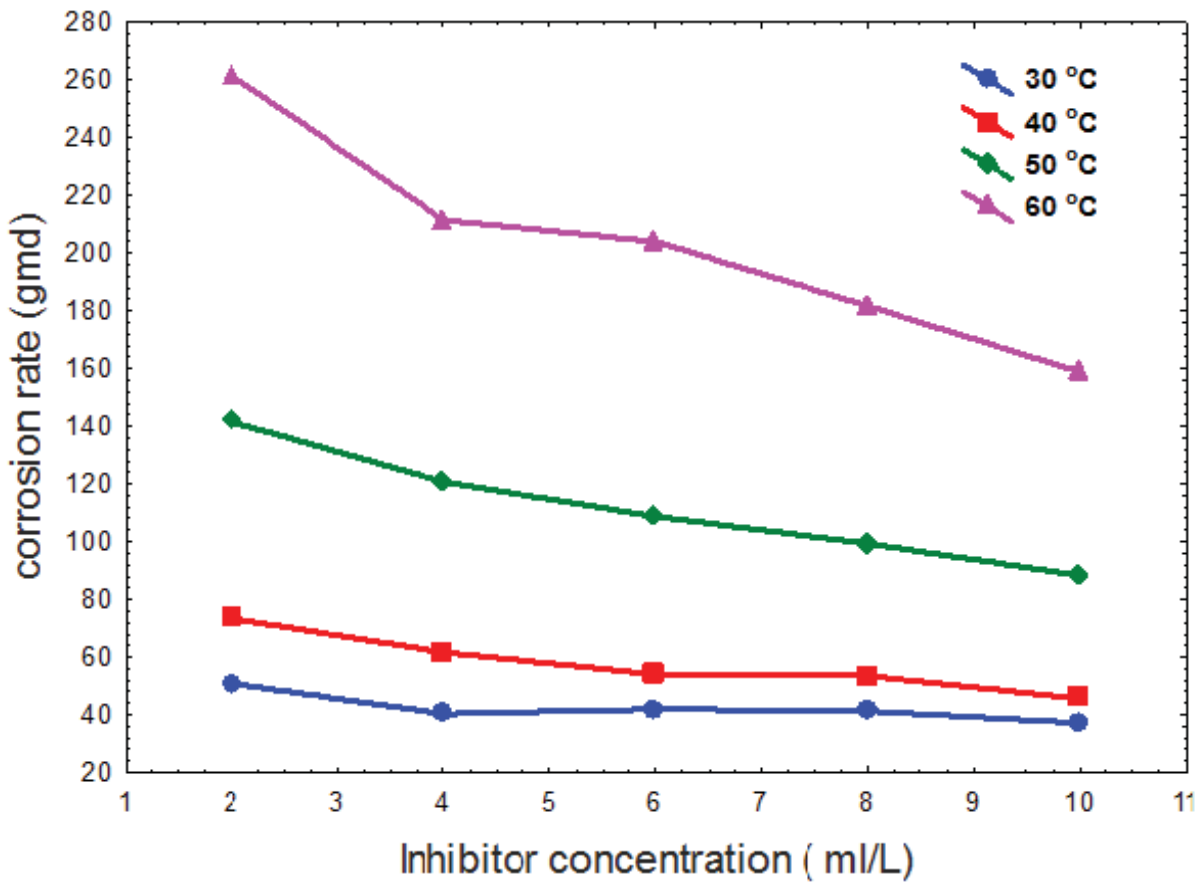

Fig (2) Impact of inhibitor concentration ( $C D L)$ on corrosive rate of mild carbon steel immersed in ( $1 \mathrm{M} \mathrm{HCl})$. 


\subsection{Temperature considerations and activation parameters}

Activation parameters such as the enthalpy adsorption $\left(\Delta H^{*}\right)$, the activation energy $\left(E_{a}\right)$ and the entropy adsorption $\left(\Delta S^{*}\right)$ they playing an significant function in comprehension of the phenomenon of adsorption of inhibitor molecules, calculates using Arrhenius equation. Eq (3) and transition state equation. Eq (4).

$$
\begin{aligned}
& \ln C R=\ln A\left[\frac{-E_{a}}{R T}\right] \\
& \ln \left(\frac{C R}{T}\right)=\left(\left(\ln \frac{R}{N h}\right)+\frac{\Delta S^{*}}{R}\right)-\left(\frac{\Delta H^{*}}{R T}\right)
\end{aligned}
$$

Where $T$ is the absolute temperature, $\mathrm{A}$ - frequency factor, $R$ - universal gas constant $(8.314 \mathrm{~J} / \mathrm{mole} . \mathrm{K}), h$ - Plank`s constant $\left(6.626 \times 10^{-34} J S\right)$ and $N$ - Avogadro`s number $\left(6.022 \times 10^{23}\right.$ molecule mol $\left.^{-1}\right)$.

$\left(E_{a}\right)$ the activation energy for mild steel in $(1 M) H C l$ in the presence of inhibitor and his absence were calculated from the Eq. (3) it can plot $(\ln C R)$ versus $(1 / T)$ as shown in figure (3), intercept and slope yield the values of $\mathrm{A}$ and $E_{a}$ whereas from Eq. (4) Can plotting $(\ln C R / T)$ versus $(1 / T)$ as shown in figure (4), straight lines obtaines with a intercept $\left((\ln R / N h)+\Delta S^{*} / R\right)$ and slope $-\left(\Delta H^{*} / R\right)$ from which values are calculated $\left(\Delta S^{*}\right.$ and $\left.\Delta H^{*}\right)$, the results are presented in the Table (2), it was observed that the activation energies in inhibited systems were less than in uninhibited systems, low values for $E_{a}$ in the existence of inhibitor ( $\left.C D L\right)$ refers to the chemical adsorption of inhibitor on the metal surface, with same behavior reported by Al- Jeilawi et al [8]. The signals values positive for $\left(\Delta H^{*}\right)$ indicate that transition state are the endothermic process of metal disintegration process, this means the disintegration of the metal is hard. in the existence of the inhibitor the negative values of the entropy activation decreases with increasing the inhibitory concentrations and refers a decrease in the entropy of system [9]. 
Table (2) Activation parameters for corrosion inhibition of mild steel surface in (1M) $\mathrm{HCl}$ in presence and absence of (CDL) extract as the corrosive inhibitor.

\begin{tabular}{|c|c|c|c|}
\hline$C_{i}(\mathrm{ml} / L)$ & $E_{a}\left(\mathrm{KJ} \mathrm{mol}^{-1}\right)$ & $\Delta H^{*}\left(\mathrm{KJ} \mathrm{mol}^{-1}\right)$ & $\Delta S^{*}\left(\mathrm{KJ} \mathrm{mol}^{-1} \mathrm{~K}^{-1}\right)$ \\
\hline 0 & 69.209 & 66.566 & 0.0195 \\
\hline 2 & 46.549 & 43.912 & -0.06822 \\
\hline 4 & 47.236 & 44.609 & -0.06764 \\
\hline 6 & 45.430 & 42.776 & -0.07390 \\
\hline 8 & 42.272 & 39.642 & -0.08425 \\
\hline 10 & 41.855 & 39.231 & -0.08662 \\
\hline
\end{tabular}

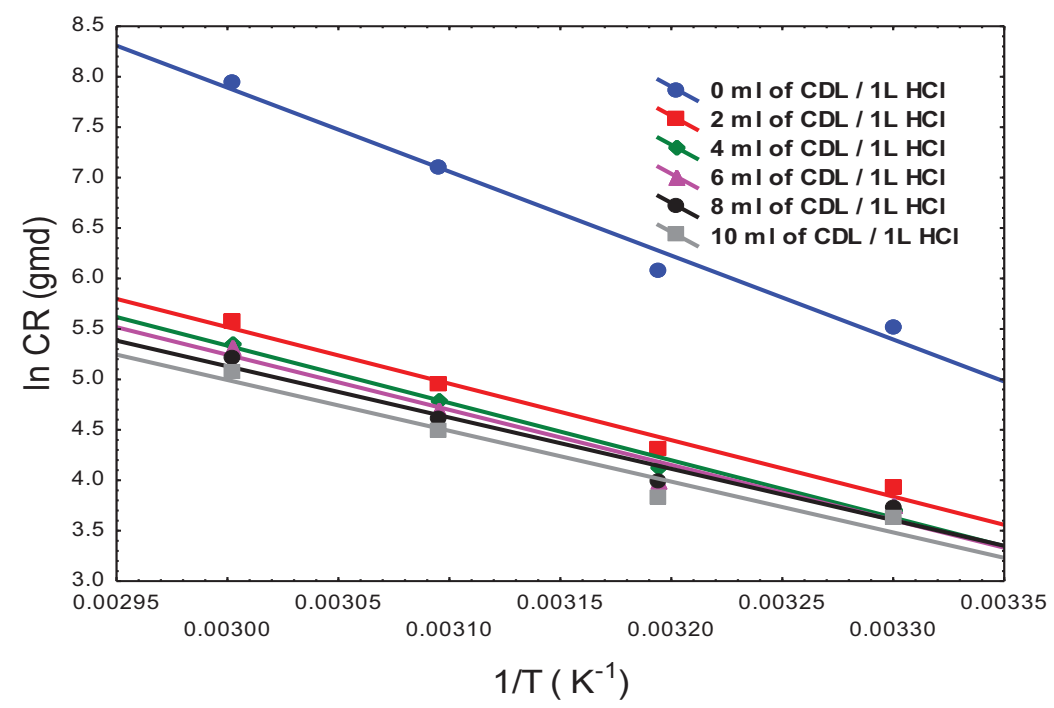

Fig. (3) Arrhenius linear plots for corrosive of mild steel surface in $(1 \mathrm{M} \mathrm{HCl})$ at various concentrations of extract $(C D L)$ and temperature range $\left(30-60^{\circ} \mathrm{C}\right)$ 


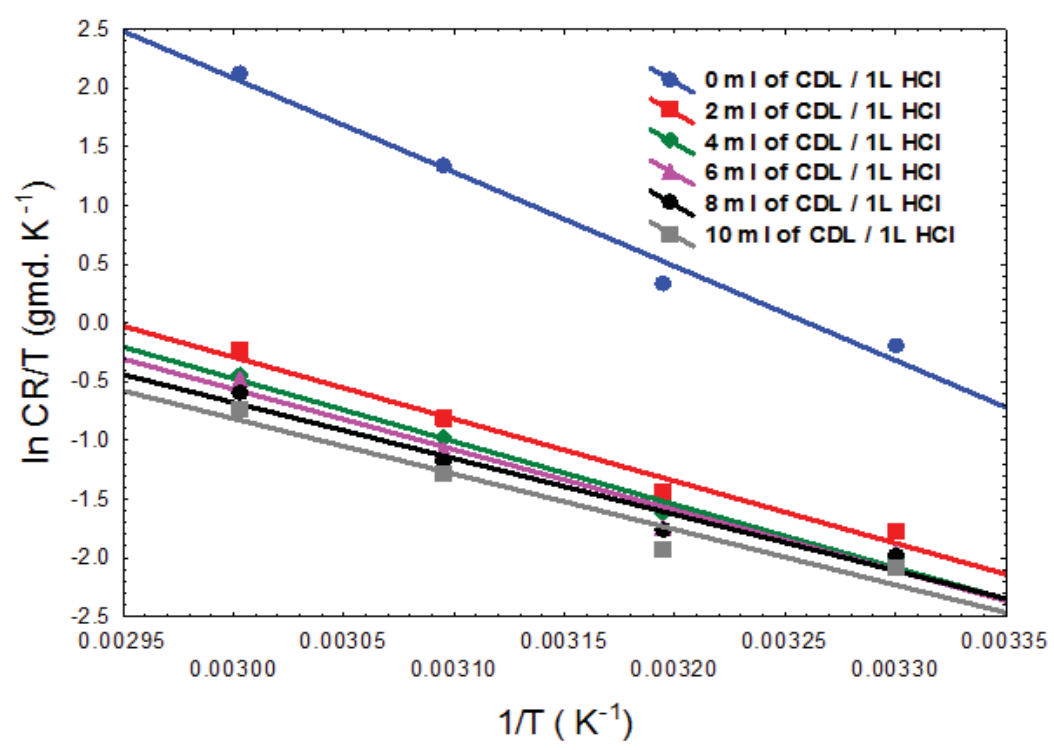

Fig. (4). Transition state linear plot for mild steel in $(1 \mathrm{M} \mathrm{HCl})$ in presence and absence of various concentrations of extract $(C D L)$.

\subsection{Effect of inhibitor concentration}

When used plant extract to inhibits corrosive of mild steel, there would be adsorption of ingredients the extract on the metal surface, leading to a larger surface coverage as a first step of the inhibition mechanism. Surface coverage $(\theta)$ data defined as part of the surface of the steel that was covered with an inhibitor are very useful during the discussion of adsorption properties, assuming a directly relation between (IE\%) and surface coverage, the expression of surface coverage it can assessed $\theta=I E \% / 100$. Suggested was two model to study the adsorption kinetics of $C D L$ on the steel surface, Langmuir adsorption isotherm Eq. (5) and Freundlich adsorption isotherm Eq. (6).

$$
\frac{C_{i}}{\theta}=\frac{1}{K_{a d s}}+C_{i}
$$

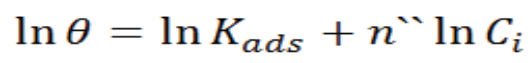

Where $I E$ is the inhibitor efficiency, $\theta$ - surface coverage, C - inhibitor concentration, n constant and $\left(K_{a d s}\right)$ - equilibrium adsorption constant. Equations (5), (6) it be plotted as explain in figures $(5,6)$. by means of equation $(7)$ can be estimated the standard free energy of adsorption. 
$\Delta G_{a d s}^{\circ}=-R T \ln K_{a d s}$

in the tables $(3,4)$ the adsorption parameters was registered, to determining the best- fit isotherm, the values were used $\left(R^{2}\right.$ correlation coefficient), by used Langmuir adsorption isotherm the higher correlation coefficients $\left(R^{2}\right)$ was obtained, it was observed that the behavior of equilibrium adsorption constant $K_{a d s}$ indicates that it increases with increasing temperature, with same behavior reported by (Rubaye et al) [10]. the values of free energy of adsorption ( $\Delta G^{\circ}$ ads $)$ negative indicate spontaneous adsorption processes and the stabilization of the adsorbent layer on the metal surface. the obtained values of the $\left(\Delta G_{\text {ads }}^{\circ}\right)$ were higher than $(-20) \mathrm{KJ} \mathrm{mol}^{-1}$ indicates two types of adsorption on steel surface, (physisorption, and chemisorption). and chemisorption plays a more important role increasing with temperature [11].

Table (3) Langmuir adsorption isotherm for extract ( $C D L)$ on mild steel surface in (1M) $\mathrm{HCl}$ at different temperature.

\begin{tabular}{|c|c|c|c|}
\hline Temperature $(K)$ & $K_{L}(\mathrm{ml} / L)^{-1}$ & $\Delta G_{\text {ads }}^{\circ} \mathrm{KJmol}^{-1}$ & $R^{2}$ \\
\hline 303 & 4.3029 & -21.082 & 0.9997 \\
\hline 313 & 4.0469 & -21.614 & 0.9997 \\
\hline 323 & 6.0938 & -23.405 & 0.9999 \\
\hline 333 & 7.8554 & -24.837 & 0.9999 \\
\hline
\end{tabular}

Table (4) Freundlich adsorption isotherm for extract (CDL) on mild steel surface in (1M) $\mathrm{HCl}$ at different temperature.

\begin{tabular}{|c|c|c|c|}
\hline Temperature $\left({ }^{\circ} \mathrm{C}\right)$ & $K_{F}(\mathrm{ml} / \mathrm{L})^{-1}$ & $n^{\prime \prime}$ & $R^{2}$ \\
\hline 30 & 1.3708 & 0.0384 & 0.9721 \\
\hline 40 & 1.5329 & 0.0439 & 0.9735 \\
\hline 50 & 1.9351 & 0.0292 & 0.9942 \\
\hline 60 & 2.1698 & 0.0231 & 0.9686 \\
\hline
\end{tabular}




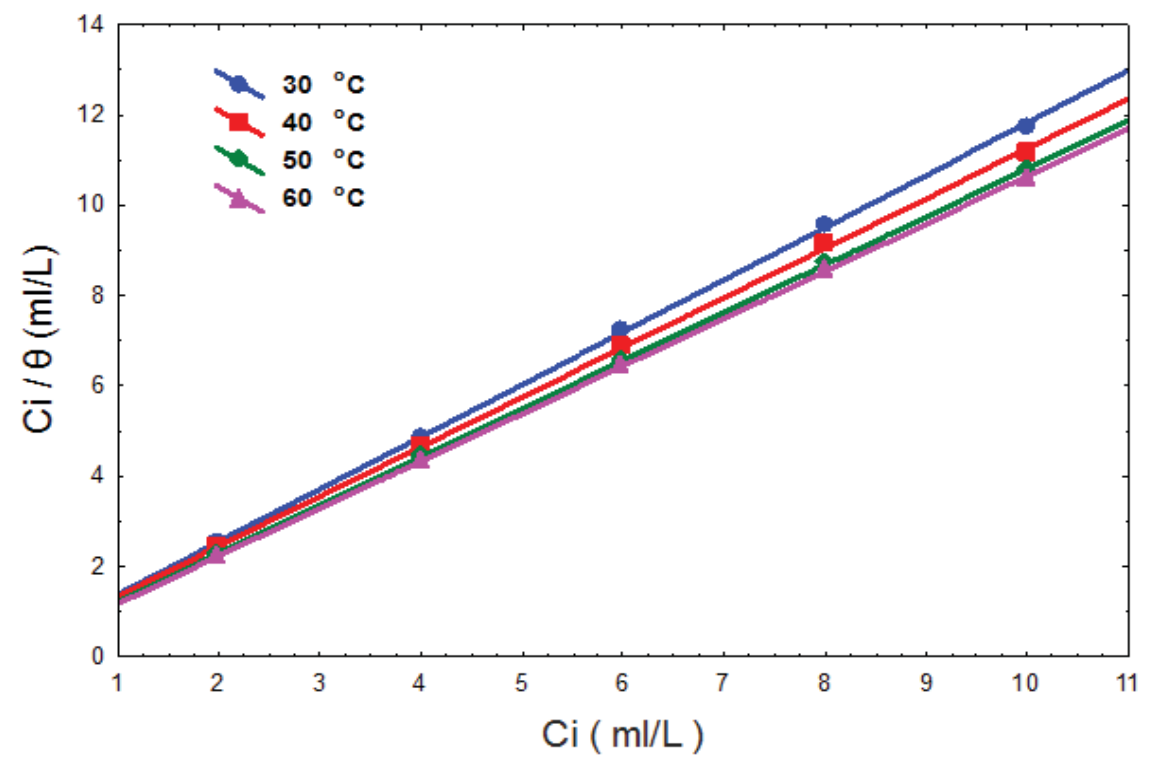

Fig. (5) Linear fitting of Langmuir adsorption isotherm for extract (CDL) on mild carbon steel in $(1 \mathrm{M}) \mathrm{HCl}$ acid.

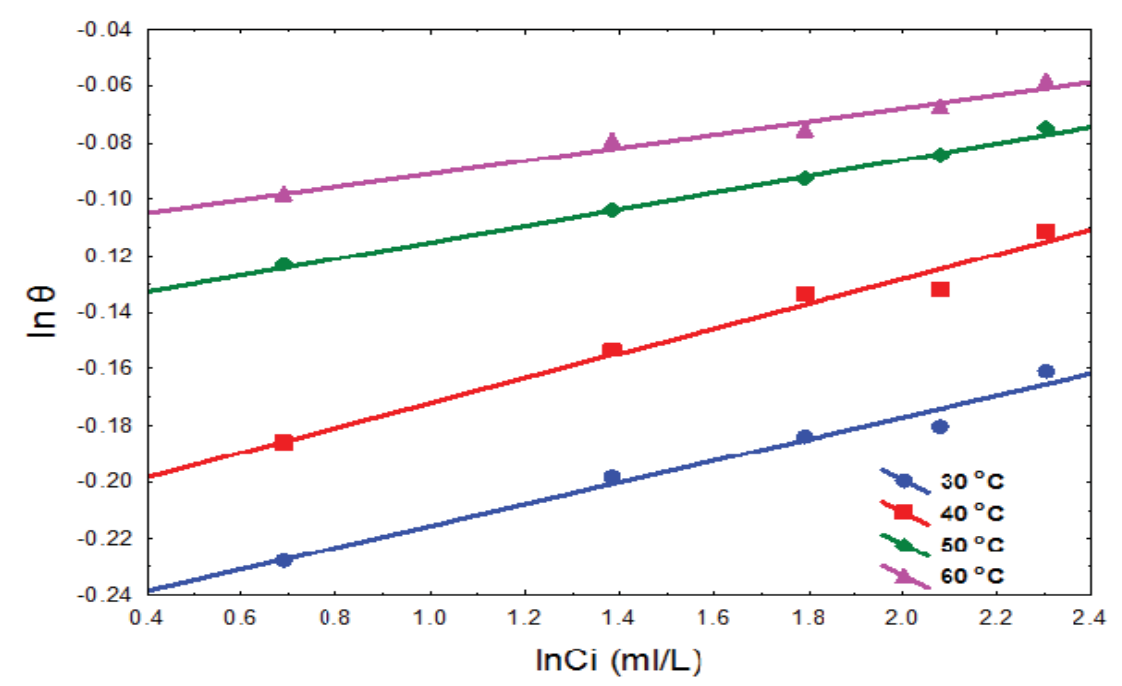

Fig. (6) Linear fitting of Freundlich adsorption isotherm for extract $(C D L)$ on mild carbon steel in (1M) $\mathrm{HCl}$ acid.

\subsection{FTIR studies}

The main step in inhibiting corrosion is the adsorption of the inhibitors on the metal surface to be protected. FTIR analysis is therefore performed to obtain some clarification in the potential interactions between the adsorbent inhibitor and mild steel surface in the acidic environment of $\mathrm{HCl} 1 \mathrm{M}$ with $10 \mathrm{ml} / \mathrm{L}$ of plant extract, the force of inhibition 
depends on the molecular composition of inhibitors, the main constituent for Cardaria draba leaf extract $(C D L)$ is a phenolic group, with same behavior reported by Al-Marzoqi et al [12]. plant leaf extract is evaluated for the assessment of major functional groups. it was observed that the FTIR spectrum of the (CDL) extract as in Figure (7-a) showed the following functional groups $(\mathrm{N}-\mathrm{H}, \mathrm{O}-\mathrm{H},=\mathrm{CH}, \mathrm{C}=\mathrm{C}, \mathrm{C}=\mathrm{O})$ which adsorbed on the surface of the metal to form a protective layer to protect it from corrosion, the peak at $3381.8 \mathrm{~cm}^{-1}$ refers to stretching frequency $N-H$, the peak at $3440 \mathrm{~cm}^{-1}$ attributed to stretching frequency $\mathrm{O}-\mathrm{H}$, the peak at $3018.2 \mathrm{~cm}^{-1}$ can be assigned to aromatic $=\mathrm{CH}$ and the peaks at $1727.3 \mathrm{~cm}^{-1}, 1636.4 \mathrm{~cm}^{-1}$ indicates the existence of a group $C=$ $O, C=C$ respectively. FTIR Spectrum for the protective layer forming on the alloy surface after exposure to $(1 \mathrm{M}) \mathrm{HCl}$ solution is shown in figure (7-b). It is found that almost all the peaks observed for $(C D L)$ extract are also observed for mild-steel immersed in (1 M) $\mathrm{HCl}$ contain $(10 \mathrm{ml} / \mathrm{L})$ of Cardaria draba leaf extract. The figure shows that there is a shift towards low frequencies, indicating that there is interaction between the inhibited particles and the surface of the steel $[13,14]$.

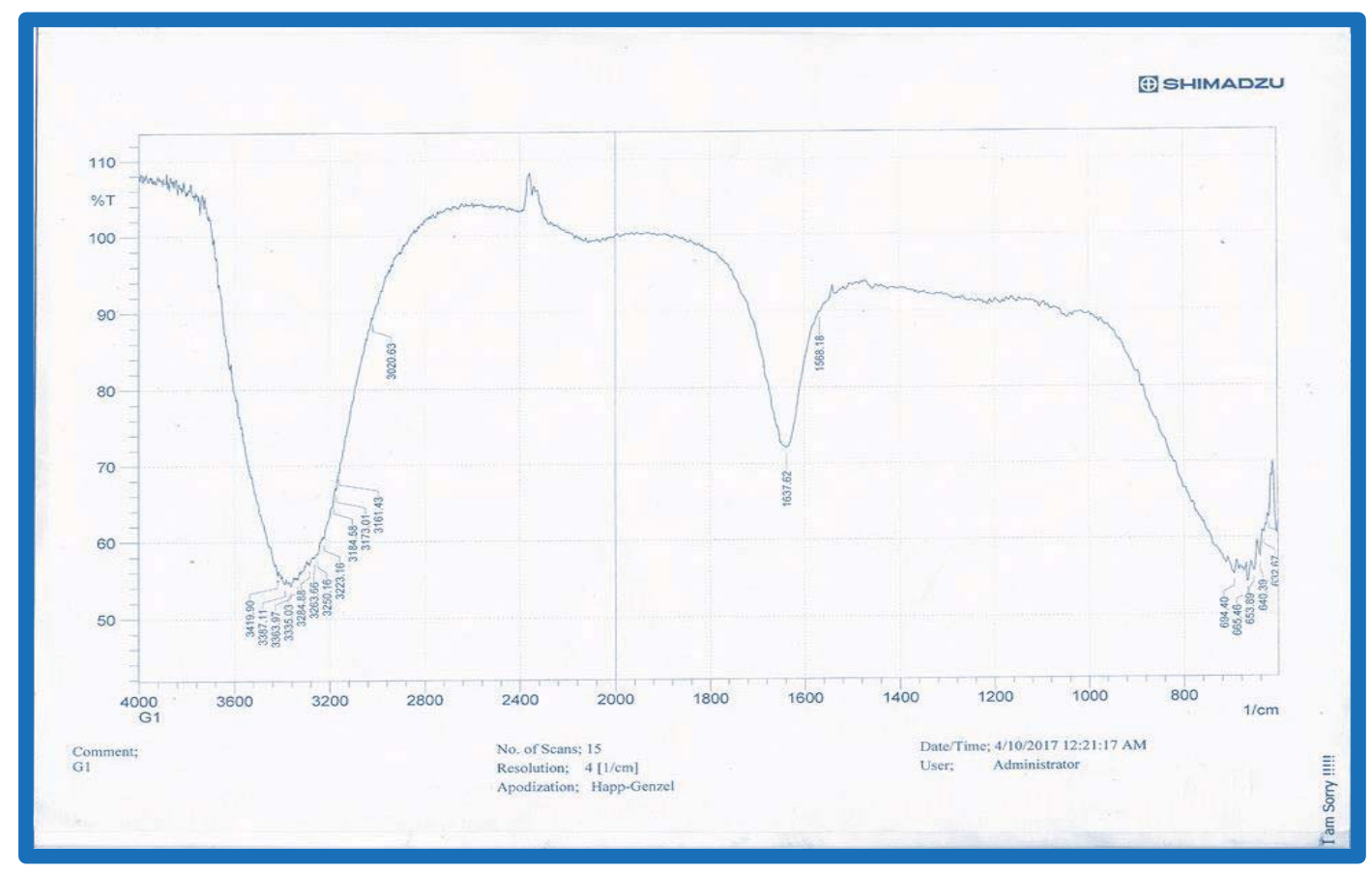

Fig. (7-a) FTIR spectrum of Cardaria draba leaves extracted with $1 \mathrm{M} \mathrm{HCl}$. 


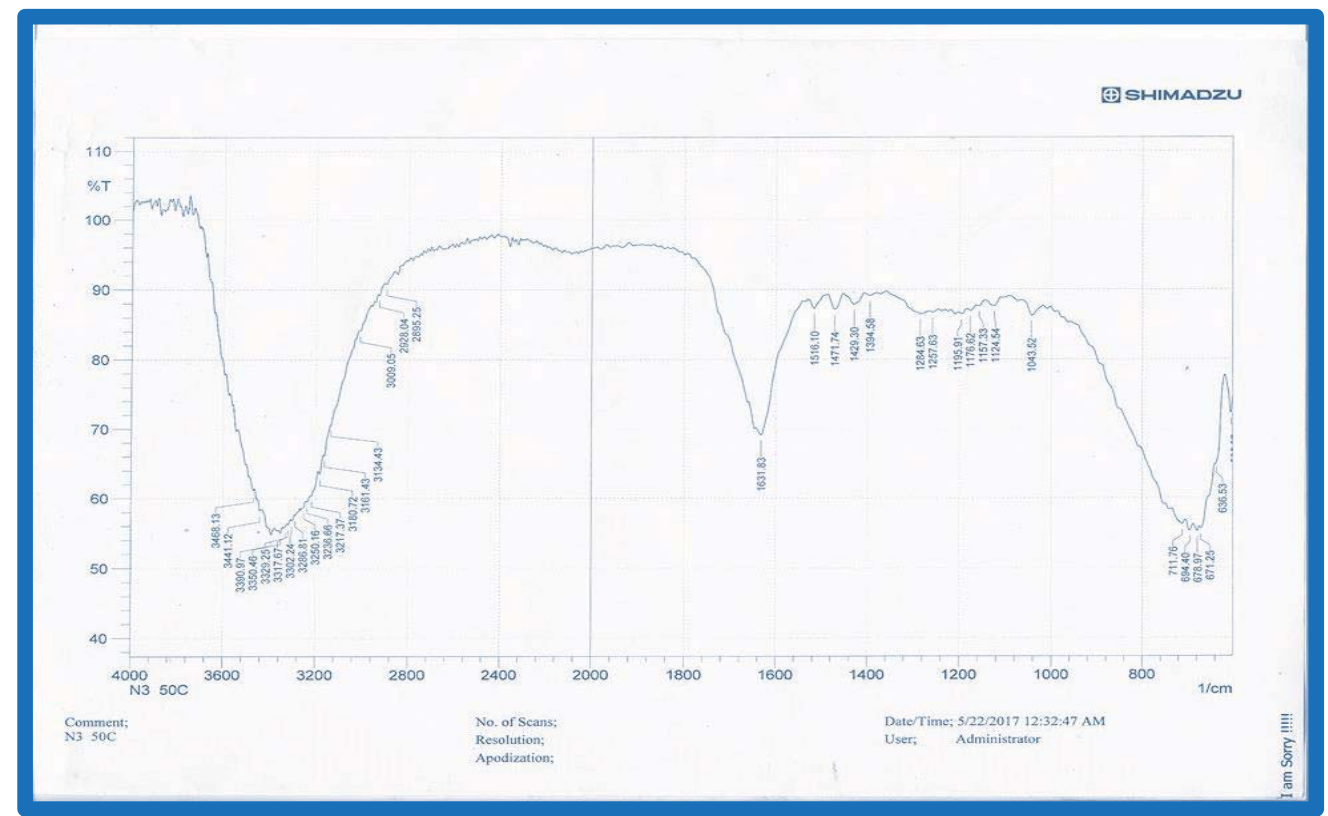

Fig. (7-b) FTIR spectrum for the protective layer formed on the metal surface after immersion in $1 \mathrm{M} \mathrm{HCl}$.

\section{5 (SEM ) Scanning Electron Microscope}

superficial analysis was performed to assess the state of surface the mild steel when exposed to the acid solution, the changes that accompany erosion and protection of the steel surface are illustrated by SEM images, SEM morphology to the mild carbon steel specimen for $3 \mathrm{~h}$ exposure in (1M) $\mathrm{HCl}$ solution with presence of inhibitor ( CDL ) and its absence are given in figure (8a-c), figure (8-a) showed the polished steel surface before Immersion in the acid-corrosion solution. as its shown in figure (8-b), the mild carbon steel surface is severely harm in the absence of inhibitor due to metal disintegration in acidic medium. Whereas in a presence of inhibitor (CDL) in (1M) $\mathrm{HCl}$ the semblance of steel surface was clearly various after addendum of inhibitor (CDL) for the corrosion medium figure $(8-c)$. The disintegration average of steel Significantly decreased and the soft surface appears by the forming of a good protection layer upon adsorption of inhibitor molecules at mild steel surface which were accountable about the inhibition of corrosive [15]. 


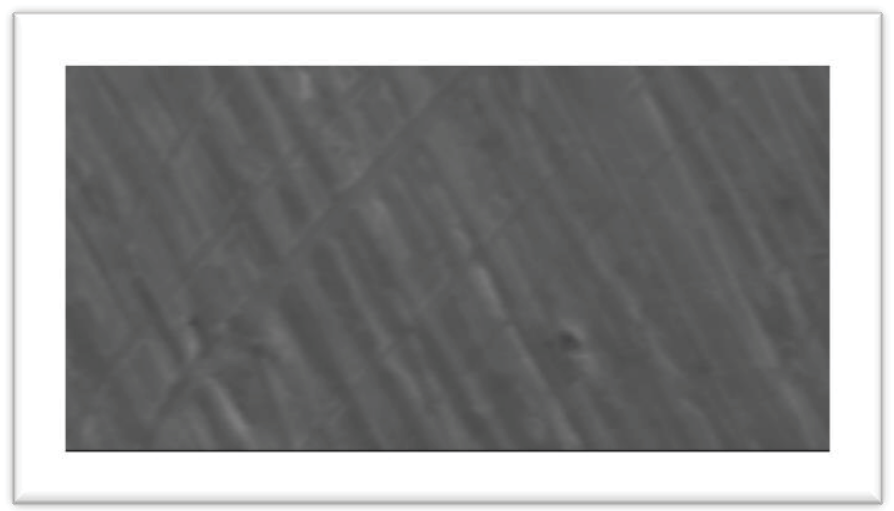

a

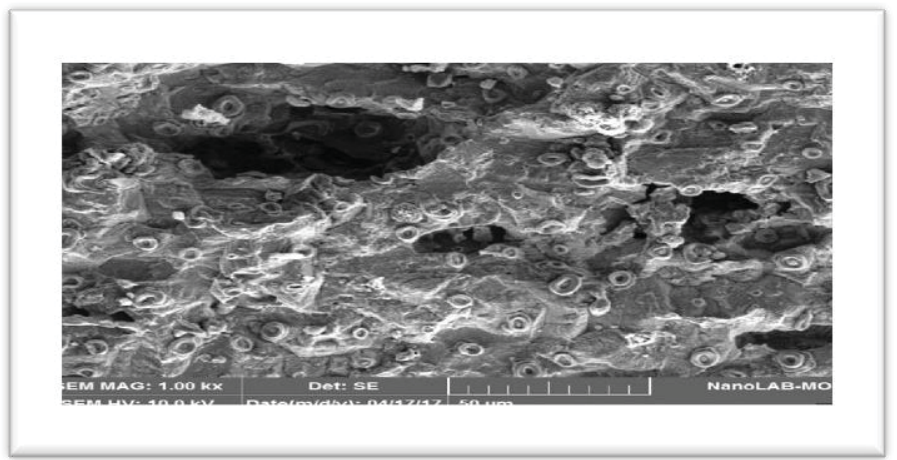

b

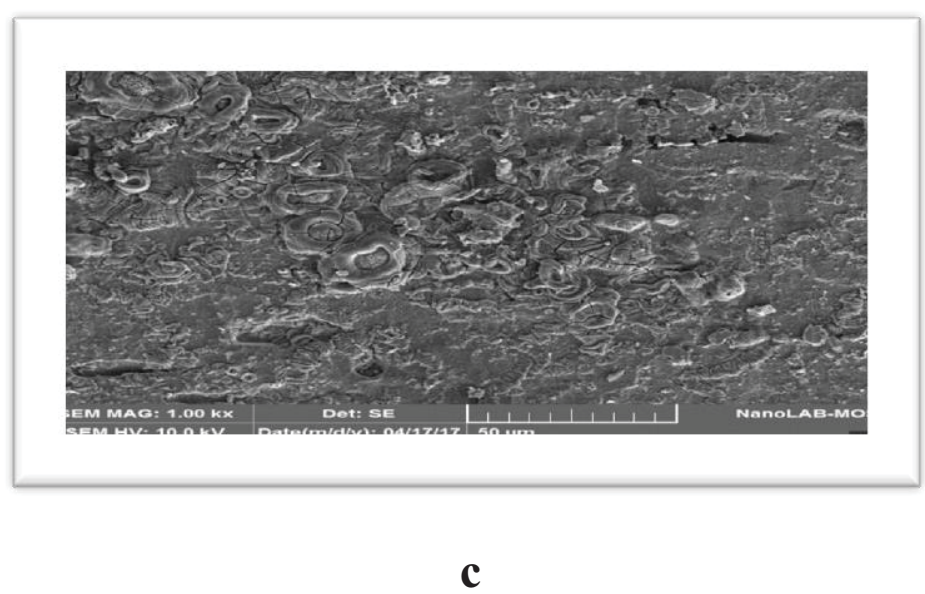

Fig (8). SEM morphology to mild steel surface at $60^{\circ} \mathrm{C}$ for 3 hours.

(a) mild carbon steel alloy before immersion in corrosion solution.(b) after exposure to (1M) $\mathrm{HCl}$ solution.(c) after exposure to (1M) $\mathrm{HCl}$ solution and in the presence of inhibitor $(C D L)$. 


\section{Conclution}

1. The results obtained from the present study showed that Cardaria draba leaf extract $(C D L)$ function as the good and effective inhibitor to the corrosive of mild steel in acidic medium.

2. It was found that adsorption of the $(C D L)$ inhibitor on the surface of the steel follow to (Langmuir adsorption isotherms).

3. The inhibition efficiency increases with increase in the concentration of the extract $(C D L)$ also with rising in temperature, where the maximum inhibition is around $(94.3 \%)$ at the ideal concentration of $(10 \mathrm{ml} / \mathrm{L})$ at $60^{\circ} \mathrm{C}$.

4. From thermodynamic values shown, the negative values of standard free energy indicate that the process of adsorption are spontaneity and endothermic.

5. The adsorption of extract molecules on surface of mild steel is due to chemical and physical adsorption (comprehensive adsorption) but chemical adsorption is the predominant mode of adsorption.

6. In the presence of a CDL extract, the activation energy decreases in the corrosion operation.

7. FTIR spectra clearly is showed the phytochemicals adsorption on mild carbon steel surface.

8. SEM morphology revealed that inhibition of corrosion was due to adsorption of $C D L$ molecules on the alloy surface.

9. It is preferable to use an acceptable plant extract for a non-toxic environment always on organic inhibitors. 


\section{References:}

1. Math Eswaran, P; Ramasamy, A.K. (2012). Corrosion inhibition of mild steel in citric acid by aqueous extract of Piper Nigrum L. E. Journal of Chemistry, 9(1): 75-78.

2. Hazazi, O.A; Abdallah, M; Gad, E. A. M. (2014). Inhibition effect of some cationic surfactants on the corrosion of carbon steel in sulphuric acid solutions: surface and structural properties. International Journal of electrochemical science, 9: 2237-2253.

3. El attari, H; Mhidra, L; chefira, K; Mengouch, S; Khamliche, L; Kheribech, A and Siniti, M. (2016) . Thermodynamic and adsorption behavior of eco - friendly 1-(2,5dioxoimidazolin-4-yl) urea on the corrosion of carbon steel in $\mathrm{HCl}$ and synergistic effect of iodide ion. International Journal of pharmaceutical science and Healthcare, 3: 116.

4. Ridhwan, A. M; Rahim, A.A, and Shah, A. M. (2012) . Synergistic effect of halide ions on the corrosion inhibition of mild steel in hydrochloric acid using Mangrove Tannin. International Journal of electrochemical science, 7: 8091-8104.

5. Fouda, A. S; Shalabi, K, and Ezzat, R. (2015). Evaluation of some thiadiazole derivatives as acid corrosion inhibitors for carbon steel in aqueous solutions. J. Mater. Environ. Sci. , 6(4) : 1022- 1039 .

6. Khadom, A.A. (2014). Dual function of benzotriazole as copper alloy corrosion inhibitor and hydrochloric acid flow improver. Surf. Eng. Appl. Electrochem, 50: 157172.

7. Anusuya, N; Sounthari, P; Saranya, J; Parameswari, K and Chitra, S.(2015). Corrosion inhibition effect of hydroxyl pyrazoline derivatives on mild steel in sulphuric acid solution together with quantum chemical studies. J. Mater. Environ. Sci., 6(6): 16061623.

8. Al- Jeilawi, R .H U; Al- Majidi, H.M.S and Al - saadie, S.A.K .(2013). Corrosion inhibition effects of some New synthesized N - Aroyl - N - Aryl thiourea derivatives for carbon steel in sulfuric acid media. Journal of Al - Nahrain university, 16 (4): 8093. 
9. Martinez, S. and Stern, I. (2002). Thermodynamic characterization of metal dissolution and inhibitor adsorption processes in the low carbon steel/mimosa tannin/sulfuric acid system. Appl. Surf. Sci., 199: 83-89.

10. Rubaye, I.Y.A; Abdul sahib, T.H and Abdul Wahid, A.A.(2015). Corrosion inhibition properties of Norepinephrine molecules on mild steel in acidic media. Journal of Encapsulation and adsorption science, 5: 155 - 164 .

11. Mohammed, K. Z; Hamdy, A; Abdel - wahab, A and farid, A.N. (2012). Temperature effect on corrosion inhibition of carbon steel in formation water by non - ionic inhibitor and synergistic influence of halide ions. Life Science Journal, 9(2) 424 - 434.

12. Al-Marzoqi, H.A; Al-Khafaji, S.M.N. and Kadhim, A.R. (2015). Influence of the crude phenolic, alkaloid and terpenoid compounds extracts of Cardaria draba (Lepidium draba .L) on human pathogenic bacteria. World Journal of Pharmaceutical Research, 4: $456-460$.

13. Leelavathi, S. and Rajalakshmi, R. (2013). Dodonaea viscosa (L.) leaves extract as acid corrosion inhibitor for mild steel - A green approach. J. Mater. Environ. Sci., 4(5): $625-638$.

14. Hussein, M.H. (2016). Determination of phytochemical composition and ten elements content ( $\mathrm{Cd}, \mathrm{Ca}, \mathrm{Co}, \mathrm{Fe}, \mathrm{Pb}, \mathrm{Mg}, \mathrm{Mn}, \mathrm{Ni}$ and $\mathrm{Zn}$ ) of Cardaria draba by $\mathrm{GC}$ MS, FTIR and AAS techniques. International Journal of Pharma and Bio Sciences, 7(3): $1009-1017$.

15. Zohdy, K. M. (2015). Surface protection of carbon steel in acidic solution using ethylene diamine tetraacetic disodium salt. International Journal of Electrochemical Science, 10: $414-431$. 